\title{
Acumulación del capital inmobiliario y apropiación social del espacio público en el Paseo de la Reforma, Ciudad de México
}

\section{Accumulation of real estate capital and social appropriation of public space in Paseo de la Reforma, Mexico City}

LISETT MÁrqueZ-LóPEZ*

\begin{abstract}
Since late 2000, Paseo de la Reforma in Mexico City, with great aristocratic historical tradition, has been transformed by national and transnational capital, with local government support, into a modern tertiary corridor reserved for corporate headquarters of large companies and high-income residents, achieving the reproduction of localized land rents, capital accumulation and the recreation of an iconic area of the modern, exclusive and exclusionary; ironically, its public space remains the scene of popular recreation and social and political protest.
\end{abstract}

Keywords: Paseo de la Reforma, tertiary urban corridor, tertiarization, postmodern urbanism, urban megaprojects, real estate capital.

\section{Resumen}

El Paseo de la Reforma en la Ciudad de México, con gran tradición histórica aristocrática, desde finales del 2000 ha sido transformado -por el capital inmobiliario-financiero nacional y trasnacional, y por el gobierno local- en moderno corredor terciario reservado para sedes corporativas de grandes empresas y residentes de altos ingresos; logrando así, reproducir las rentas del suelo localizadas, acumular capital y recrear un área icónica de la posmodernidad, exclusiva y excluyente; contradictoriamente, su espacio público sigue siendo escenario de la recreación popular y la protesta social y política.

Palabras clave: Paseo de la Reforma, corredor urbano terciario, terciarización, urbanismo posmodernista, megaproyectos urbanos, capital inmobiliario. 


\section{Introducción}

La Zona Metropolitana del Valle de México (zMvm) es hoy una de las más grandes aglomeraciones urbanas de América Latina y del mundo. A lo largo del siglo xx, la metrópoli se convirtió en la mayor concentración demográfica y económica -industrial, comercial, bancaria, financiera y de servicios del país. La Ciudad de México, núcleo fundamental de la metrópoli, capital del país que acoge a los poderes federales y a las sedes de las organizaciones políticas, empresariales y sociales más destacadas, por lo cual es el centro administrativo más importante en el ámbito nacional, y cuenta con una amplia infraestructura urbana, cultural, educativa, de salud y de investigación científica. La ZMvM es, por lo tanto, una metrópoli de alto grado de complejidad estructural y morfológica.

Durante cuatro décadas (1940-1980) la Ciudad de México y la zona metropolitana, que se estructuró a partir de ella, fueron el motor del crecimiento económico nacional y la punta de lanza del proceso de industrialización por sustitución de importaciones. En 1983 se inició la implantación de un nuevo patrón de acumulación de capital de corte neoliberal, en función del cual se puso en marcha el debilitamiento de la política intervencionista del estado, la apertura de la economía mexicana hacia el exterior, la privatización de las empresas públicas, la modernización y la flexibilización de los procesos de trabajo mediante el uso de nuevas tecnologías, el debilitamiento de las organizaciones sindicales y la contracción del salario real (Pradilla-Cobos, 2009).

Este nuevo patrón de acumulación se formalizó mediante la incorporación de México al Acuerdo General sobre Aranceles y Comercio (GATT) en 1986 y con la firma en 1993 del Tratado de Libre Comercio de América del Norte (TLCAN) que empezó a operar en enero de 1994. Con la apertura comercial y la inserción del país en la globalización, la economía de la metrópoli ha experimentado un acelerado proceso de desindustrialización y terciarización polarizada, que han generado impactos económicos, sociales y territoriales importantes (Pradilla-Cobos et al., 2012).

En este contexto se ha consolidado una nueva lógica de estructuración urbana en la zMvм y, especialmente, en la Ciudad de México, que modifica a la organizada a partir de una centralidad y varios subcentros: la configuración de una compleja red de corredores urbanos de especialización terciaria (Pradilla-Cobos et al., 2008; Pradilla-Cobos, 2013).

Este amplio sistema de corredores terciarios se extiende a lo largo de los principales ejes viales y de desplazamiento de mercancías y personas de la ciudad, concentrando aceleradamente a los inmuebles que alojan a centros comerciales y comercios aislados, servicios financieros (oficinas de grupos financieros, bancos, casas de bolsa, etc.), servicios al turismo y 
actividades conexas (hotelería, restaurantes, agencias de viajes y compañías de aviación, etc.), oficinas de gestión gubernamental y privada, centros recreativos y culturales públicos y privados, o combinaciones de estas actividades, etc., modificando notoriamente la estructura, la forma urbana y la apropiación del espacio público.

Entre los múltiples corredores que arman esta red destaca el conformado a lo largo del otrora imperial y señorial Paseo de la Reforma en el tramo comprendido entre el Anillo Periférico y Puente de Alvarado. El objetivo principal de este artículo consiste en analizar las transformaciones arquitectónicas y urbanas que se han suscitado a lo largo del tiempo en el Paseo de la Reforma, y los impactos territoriales y sociales al convertirse éste en un corredor urbano terciario.

Para entender cómo se llevó a cabo dicho proceso, partimos del análisis de la evolución histórica del Paseo de la Reforma: su surgimiento, construcción y ampliación; su primera transformación urbana comercial y cómo repercutieron en este espacio diversas etapas como la industrialización de la ciudad, la crisis de 1982 y los sismos de 1985, la reestructuración del capitalismo mexicano y, finalmente, los cambios que han acompañado a las tres últimas administraciones gubernamentales del Partido de la Revolución Democrática (PRD), autodefinido como partido de izquierda.

Metodológicamente, el trabajo de investigación del cual se desprende este artículo, combinó técnicas cuantitativas como el análisis de estadísticas de censos de población (2000 y 2010) y de actividades económicas (1998, 2003, 2008), un levantamiento de usos del suelo de cada uno de los inmuebles que ocupan los predios, levantamiento fotográfico y revisión de información factual periodística y bibliográfica; así como técnicas cualitativas que incluyeron entrevistas no estructuradas, en profundidad, a actores claves en el proceso, y observación directa de los usos del espacio público.

Desde su gestación en 1866, el Paseo de la Reforma ha sido uno de los ejes socioterritoriales fundamentales de la estructuración de la Ciudad de México, de su expansión y conversión en la gigantesca metrópoli del Valle de México, de sus sucesivas restructuraciones y su funcionamiento actual. $\mathrm{Al}$ mismo tiempo, ha sido uno de los ámbitos territoriales privilegiados de localización de actividades económicas preeminentes, y de residencia de las clases dominantes capitalinas, a las cuales ha simbolizado.

Como suelo apropiado privadamente y mercantilizado, y como emplazamiento de sucesivos proyectos constructivos de inmuebles diseñados por reconocidos arquitectos, el área urbana que recorre y a la que sirve de paseo ha sido soporte de intensos procesos de reproducción del capital inmobiliario. El uso privado de los inmuebles que lo bordean se ha rela- 
cionado cambiantemente con el uso público del paseo mismo, unas veces en concordancia, otras en oposición o conflicto.

El Paseo de la Reforma ha sido gestado, promovido y, en distintos momentos, apropiado por el poder político nacional y local, se le ha revestido con los símbolos de la historia oficial, teñido con sus diversas ideologías, promoviendo su uso recreativo, festivo y popular, como formas de reproducirlas. También, paradójicamente, ha expresado las ideologías que se le oponen y las demandas reivindicativas de los sectores populares, convirtiéndose en ámbito de manifestación y despliegue de las contradicciones sociales y políticas. Al mismo tiempo ha sido un ámbito urbano vivo, contradictorio, a lo largo de su historia; y hoy aparece como un ícono de la ciudad, un instrumento del discurso político, del dominante y del dominado y, a la vez, como un valor de cambio inmobiliario en el llamado mercado global de las ciudades.

\section{El origen del Paseo de la Reforma}

El Paseo de la Reforma fue producto de las circunstancias históricas -económicas, políticas y culturales- de la segunda mitad del siglo xIx; surgió del poder imperial impuesto por Europa para responder a sus necesidades de operación cotidiana: el diario tránsito del emperador Maximiliano desde Chapultepec al Palacio Nacional en el centro; y de la legitimación social mediante la construcción de obras monumentales "modernizadoras" en la Ciudad de México, entonces capital del imperio.

En su diseño formal inicial subyacía la visión europea de la ciudad imperial napoleónica, París, reconstruida a la manera del Barón de Haussmann, para enfrentar en mejores condiciones militares las revueltas obreras contra el poder de la burguesía y, a la vez, adecuarla a las necesidades inmobiliarias del capital en ascenso.

Premonitoriamente, el modelo político-ideológico del paseo estaba permeado por las contradicciones entre la monarquía y la república, el capital y el proletariado parisino; y el producto-resultado hecho vialidad urbana en la capital mexicana mostraría también las contradicciones históricas de México en ese momento. La materialización de la idea del paseo se enfrentó a las vicisitudes de la lucha político-militar entre invasores extranjeros e invadidos, conservadores y liberales, monárquicos y republicanos mexicanos.

El paseo se construyó cuando Maximiliano, su diseñador, ya había sido derrotado y ejecutado por Benito Juárez, cuando ya se había aplicado la desamortización-nacionalización y privatización liberal de los bienes de las comunidades religiosas e indígenas mediante la Ley Lerdo que facilitó la urbanización del ámbito territorial, y cuando el general liberal Porfirio Díaz 
ya había abandonado las ideas republicanas para convertirse en dictador y, en función del desarrollo capitalista, aplicaba medidas expropiatorias y represivas contra el campesinado pobre que obraría como caldo de cultivo de la Revolución mexicana (Gilly, 2007).

Mediante el instrumento de la Ley Lerdo, que fue al mismo tiempo anticlerical y anticomunitaria indígena, se abrió a todo lo largo del paseo una extensa zona para la expansión urbana y la especulación con el suelo, que fue apropiada inicialmente como área residencial por los sectores de altos ingresos de la sociedad capitalina, nacionales y extranjeros; igual destino corrió el paseo mismo, construido como eje de su recreación y vida festiva. Tuvo lugar, por tanto, la consonancia entre el uso privado de los inmuebles y el uso público de la vialidad, apropiados ambos por la aristocracia y la alta burocracia adinerada.

\subsection{Maximiliano y el trazo de una calzada rectilinea}

Cuando Maximiliano llegó a México, trajo consigo la influencia del urbanismo de Eugene Georges Haussmann en su idea de crear una ciudad imperial. Esta visión se plasmó en sus proyectos urbanísticos. Con esta influencia, Maximiliano encargó el trazo de la futura calzada, (JiménezMuñoz, 1994). Para iniciar su construcción fue necesario adquirir los terrenos por donde se realizaría. El plan del emperador de unir el Castillo de Chapultepec con la Plaza Mayor de la ciudad, no se limitaba a la creación de una gran calzada, pensaba incluir en su proyecto la construcción de diversos edificios de utilidad pública (Arciniega-Ávila, 1994). De tal forma que en 1785 se edifica una mansión de descanso para los virreyes de la Nueva España, misma que funcionó como tal hasta 1825 , posteriormente se adaptó como Colegio Militar; en 1864 el inmueble formó parte fundamental del plan para construir la calzada real, al ser usado, por órdenes del emperador, como residencia imperial.

Para 1866 se habían concluido sólo algunos tramos del Paseo del Emperador. Sin embargo, a lo largo de la calzada, según un reglamento de la época, se prohibía:

El paso de carros de cualquier clase por la nueva calzada; se establecía que en los paseos donde existieran contracalzadas, estás estarían destinadas al paso exclusivo de personas a pie, sin que por ellas pudieran transitar caballos, ni ningún animal; así mismo, se prohibía el paso por la calzada de entierros, reuniones de música o procesiones, sin el consentimiento del emperador. Pasar por alto estas disposiciones se castigaría con una multa (Gómez, 1994: 36).

El proyecto de Maximiliano de edificar un gran paseo al estilo de Haussmann quedó inconcluso y sin embellecimiento alguno, debido a la 
caída del imperio en 1867, el fusilamiento de Maximiliano y el retorno de Juárez al poder, después de luchar cuatro años contra la intervención y el imperio.

\subsection{El gobierno de Juárez y la Calzada Degollado}

La situación económica y social después de las prolongadas luchas por el triunfo de la república hizo que Benito Juárez centrara su interés en la reorganización de la economía del país. En este periodo no se prosiguió con el desarrollo del paseo; sin embargo, se expidieron decretos importantes que posteriormente serían aprovechados por los propietarios de tierras urbanizables. Entre los que destacan: el decreto del 13 de marzo de 1861, mediante el cual se exceptuaba a los colonos extranjeros del pago de contribuciones durante cinco años y se les eximia de la contribución económica de derechos de importación de insumos para la formación y funcionamiento de las colonias; el 6 de febrero de 1861 se eliminó el derecho de traslado de dominio y se les dieron facultades a los propietarios de las fincas rústicas y urbanas para subdividirlas con su parte proporcional de gravamen hipotecario, favoreciendo a aquellos fraccionamientos de mexicanos que incorporaran extranjeros entre su población, promoviendo así la apertura a inversionistas extranjeros (Jiménez-Muñoz, 1993).

El 19 de febrero de 1872, por órdenes del presidente Juárez, se invalidó el carácter exclusivo para el Paseo de la Reforma que había adquirido la vía durante el imperio de Maximiliano, convirtiéndose en paseo público. El Paseo del Emperador adoptó el nombre de Calzada Degollado, en honor al general José Santos Degollado.

\subsection{El nacimiento del Paseo de la Reforma}

Después de la muerte de Juárez en 1872, asumió la presidencia Sebastián Lerdo de Tejada, quien estableció, el mismo ańo, mediante decreto el renombramiento de la calzada, denominándola Paseo de la Reforma, en honor al triunfo de los liberales y a la promulgación de las Leyes de Reforma, implementadas durante la presidencia de Benito Juárez. En este ańo, Lerdo de Tejada decretó que el Castillo de Chapultepec funcionara como residencia oficial, y durante su periodo presidencial se iniciaron las primeras obras de diseño y urbanización del paseo.

En 1873, se amplió el paseo, alcanzando una anchura de 25 metros en la parte central y 10 metros en cada una de las banquetas laterales. Se le añadieron dos franjas a ambos lados para darle más amplitud, se sembraron hileras de fresnos y sauces a lo largo de ellas, se colocaron las primeras bancas, de tal manera que en el centro se formará un andador. 
Asimismo, se proyectaron cuatro glorietas más, aparte de la que dejó inconclusa Maximiliano (Martínez-de la Macorra y Juárez, 1994).

\subsection{El esplendor del Paseo de la Reforma durante el Porfiriato}

Mediante el autoritarismo, Porfirio Díaz logró establecer la paz social y la estabilidad política, indispensables para impulsar el desarrollo económico capitalista, para lo cual aplicó un proyecto de desarrollo en el que se privilegiaba fundamentalmente a la inversión extranjera, ampliamente favorecida en la construcción y operación de los ferrocarriles, la generación de energía eléctrica, la explotación petrolera y la propiedad territorial.

Estas inversiones le permitieron a la Ciudad de México contar con el financiamiento necesario para iniciar la construcción de la infraestructura de una ciudad "moderna", a la manera de las urbes europeas, que debía satisfacer las necesidades de la oligarquía local y garantizar con su imagen la atracción del capital extranjero, para lo cual fue necesario destinar significativas sumas al arreglo de las calzadas y paseos, promoviendo la realización de lujosas obras arquitectónicas y monumentos (GayónCórdova, 1987).

Durante el Porfiriato, la lotificación de terrenos y la construcción de inmuebles y obras públicas fueron realizadas por miembros de la elite cercanos al círculo de Porfirio Díaz, quienes en su mayoría ocupaban importantes puestos de gobierno y al mismo tiempo se integraban a las actividades bancarias, inmobiliarias y urbanizadoras de la Ciudad de México (Jiménez-Muñoz, 1993). Esta posición les permitió obtener terrenos agrícolas bien localizados para fraccionarlos y posteriormente iniciar su proceso de urbanización, introduciendo en ellos redes de servicio público. El desarrollo urbano terminó convertido en un negocio territorial apoyado por la venta de terrenos y la concesión a compañías extranjeras.

En este periodo, no existía un modelo de planeación, aunque los esfuerzos urbanizadores se basaban en la organización de las ciudades europeas, específicamente en la aplicación del proyecto de Haussmann, promoviendo el trazo de nuevas y amplias calles y edificaciones que modificaban el perfil urbano. El crecimiento de la ciudad hacia el poniente se inició carente de un proyecto de desarrollo urbano, siendo los fraccionadores de elite, interesados en los negocios lucrativos y la especulación, los responsables de la urbanización.

En el Porfiriato, el Paseo de la Reforma adquirió realmente el carácter de "paseo imperial", que Maximiliano no logró concretar, y se estableció la vocación y la función de la calzada; Díaz tomó como residencia el Palacio de Chapultepec, se inició la dotación de servicios, posteriormente la densi- 
ficación de la zona y con ello una gran valorización de los terrenos habitados por la alta burguesía de la ciudad. Se empezaron a construir lujosas residencias de estilo europeo en ambos lados del Paseo de la Reforma, dotadas con los mejores servicios, adquiendo así, un gran prestigió y convirtiéndose en la zona más cara de la ciudad; a lo largo de éste se instalaron las clases económicas más poderosas y privilegiadas: capitalistas extranjeros, miembros de la vieja aristocracia, nuevos ricos e incluso funcionarios.

El Paseo de la Reforma era el espacio público predilecto de la ciudad, en el cual poco a poco se fueron asentando magnas casas de campo, lujosos hoteles, elegantes cafés y establecimientos recreativos. Reforma fue uno de los ejes organizadores de la expansión de la urbanización sobre la periferia, como ámbito privilegiado para el negocio con el suelo urbano, y lugar de segregación habitacional y recreativa de las clases sociales dominantes.

Al mismo tiempo, los gobernadores y la naciente burguesía mexicana concedieron al paseo una identidad ideológica espuria entre la nación: la dependencia del extranjero, el desarrollo urbano elitista, la burguesía y el poder político, la cual parece haberse perpetuado, cristalizado, materializado desde entonces y hasta nuestros días en el Paseo de la Reforma.

\section{El Paseo de la Reforma y sus transformaciones en el siglo $\mathrm{xX}$}

El Paseo de la Reforma fue un eje estructurante importante en la expansión de la ciudad a finales del siglo xIx y la primera mitad del siglo Xx, cuando su traza sirvió de vector e instrumento de la construcción de nuevas colonias residenciales, o luego de los ańos treinta cuando se prolongó hacia el poniente, más allá del Bosque de Chapultepec, simultáneamente con la formación de nuevas colonias residenciales para sectores de altos ingresos como Polanco y Lomas de Chapultepec, las cuales se han beneficiado desde su construcción y hasta ahora de las ventajas ambientales y de paisaje, y de su expresión en la evolución de las rentas del suelo, otorgadas por la presencia del mayor espacio público verde de la ciudad: el Bosque de Chapultepec, y las instalaciones recreativas y culturales que fueron ubicándose en su interior.

\subsection{El inicio de la industrialización y la metropolización}

Más tarde, en el periodo 1940-1970, caracterizado por la industrialización y mercantilización del país y la capital y por la urbanización acelerada, Reforma desempeñó un papel determinante en la ampliación de la centralidad urbana a partir del Centro Histórico - lo que fue la ciudad en la Colonia- transformándose en eje hotelero de lujo, área de gestión empresarial y de recreación masiva, sobre todo mediante el emplazamiento 
de grandes salas de cine (Alfaro y Ochoa, 1997) y la construcción de edificios de oficinas para la gestión pública y privada.

\subsection{La terciarización del Paseo de la Reforma}

La transformación del paseo, de eje articulador de una zona de vivienda de altos ingresos, en eje terciario, a partir de la destrucción de los antiguos inmuebles de vivienda y la densificación inmobiliaria, permitió una nueva fase de recuperación de rentas del suelo, la generación de nuevas y la valorización de capitales en la construcción de los inmuebles cuyo uso era entonces la reproducción del capital.

El paseo se convirtió en el escaparate de las nuevas corrientes de la arquitectura moderna, presentando una marcada influencia de la arquitectura norteamericana, la cual era desde mediados de la década de los veinte, el modelo para un amplio sector de arquitectos mexicanos, que sustituyó a las grandes creaciones europeizantes del siglo XIX (Martínez-Assad, 2005). Reforma empezaba a ser el eje-simbólico de una gran ciudad que transitaba hacia la "modernidad capitalista".

Esta función se mantuvo en la fase en la que la expansión de la metrópoli dio lugar al surgimiento de subcentralidades en los pueblos tradicionales absorbidos por ella o en las nuevas periferias alejadas del centro, para atender las necesidades de abasto de mercancías y servicios de consumo inmediato para la población.

Al mismo tiempo, el Paseo de la Reforma fue uno de los principales ejes de la metropolización hacia el poniente y el norte a través del Anillo Periférico luego de su construcción a fines de los años sesenta, sirviendo a la movilidad entre el Centro Histórico, la centralidad ampliada y las ciudades de Toluca y Querétaro, actuando también como factor y referente de la valoración de lo urbano (Terrazas-Revilla, 2005). Posteriormente, siguió una tendencia al desarrollo lineal que se consolidó en las décadas siguientes, para conformar uno de los más importantes corredores urbanos terciarios de la metrópoli con una enorme carga simbólica heredada de su pasado aristocrático.

Las formas de apropiación del paseo cambiaban notoriamente: el uso privado, empresarial y mercantil de los inmuebles que bordeaban el paseo se combinó con el uso público de la vialidad convertida en eje de acceso a las actividades allí localizadas, incluidas las de recreación mercantil de masas y de comunicación metropolitana. En el tramo del Bosque de Chapultepec, que se fue poblando de inmuebles y ámbitos culturales y recreativos públicos de importancia nacional (Museo de Antropología, Museo de Arte Moderno, Auditorio Nacional, Zoológico), el uso ciudadano masivo no interfirió con su función de valorización de las áreas de residen- 
cia de altos ingresos en proceso de transformación en ámbitos terciarios, como el caso de Polanco.

El paseo empezó a servir también como lugar público para la realización de mítines y manifestaciones de protesta de organizaciones populares y políticas de oposición al régimen del Partido Revolucionario Institucional, que entraban en conflicto tanto con el contenido simbólico otorgado por el poder político, como con las actividades privadas mercantiles, turísticas y de gestión del capital.

\section{El neoliberalismo y la transformación en curso}

El cambio del patrón de acumulación de capital, del intervencionista al neoliberal, iniciado luego de la recesión de 1982, abrió el camino a una nueva transformación del Paseo de la Reforma, un ámbito afectado seriamente por el sismo de 1985, tanto en sus funciones urbanas generales, como en su apropiación diferencial y contradictoria por el uso privado y el público, y por los distintos sectores sociales.

\subsection{La recuperación inmobiliaria de Reforma}

Los sismos de 1985 impactaron notoriamente a lo largo del trazo de Reforma centro, deteriorando o destruyendo varios de sus inmuebles, propiciando una reserva de terrenos baldíos e inmuebles deteriorados. Los efectos del sismo profundizaron el estancamiento que sufría el paseo en términos de construcción de inmuebles y valorización del suelo; pero paradójicamente, la destrucción y el estancamiento constructivo crearon condiciones favorables para el boom inmobiliario posterior, pues mantuvieron relativamente estables los precios de los terrenos y aportaron predios al mercado del suelo.

La liberación de los flujos internacionales de capitales y su libre entrada al país, consustanciales a la aplicación del patrón neoliberal de acumulación de capital, aplicados de 1986 en adelante, abrieron el camino al ingreso del capital financiero trasnacional que se asoció con el capital inmobiliario nacional o actuó por su cuenta, siendo factor fundamental en el impulso a las grandes construcciones en Santa Fe, Reforma y Polanco.

A principios de la década de los noventa, el proyecto Santa Fe, promovido directamente por el gobierno del presidente Carlos Salinas y su regente capitalino Manuel Camacho, con el organismo Servimet como ámbito de inversión inmobiliaria, se benefició del estancamiento en que se encontraba Paseo de la Reforma desde el sismo de 1985 que lo afectó seriamente. Santa Fe también se benefició en el gobierno de Andrés Manuel López Obrador (AMLO), debido a la elevación de los índices de 
construcción que permitieron liberar la altura de los edificios, y de la construcción de proyectos de vialidad para mejorar la conectividad durante el gobierno de Ebrard: la Supervía, ya concluida, y el túnel Santa FeReforma, que debido a la crisis económica del 2009, quedó en espera de capitales privados interesados en realizarla.

Pero la situación de estancamiento de Reforma cambió luego de la firma y entrada en vigor, en 1994, del TLCAN. Surgieron grandes expectativas de negocios inmobiliarios en el submercado de inmuebles de oficinas de lujo y para el turismo, y edificios mixtos de vivienda, comercio, oficinas, hotelería, etc., que se dirigieron hacia el proyecto Santa Fe y hacia el Paseo de la Reforma donde se proyectaron varias torres; pero la materialización de esos grandes proyectos diseñados fue truncada o pospuesta por el "error de diciembre" de 1994 y la recesión de 1995.

La recuperación económica posterior a la crisis de 1995, y sobre todo el impulso dado por los gobiernos "de izquierda" de la capital iniciado en 1998, cuando el entonces Jefe de Gobierno del Distrito Federal, Cuauhtémoc Cárdenas, tras haber aprobado el proyecto de construcción de la Torre Mayor, colocó la primera piedra, logrando una inversión extranjera significativa y la construcción de uno de los primeros edificios imponentes sobre el corredor.

Sin embargo, a partir del 2001, durante el gobierno de López Obrador y posteriormente en el de Ebrard Casaubon, a partir de la aplicación del Bando 2, los estímulos fiscales y las facilidades administrativas a los constructores, así como los programas de inversión pública para la revitalización del corredor Reforma; políticas selectivas cuyo objetivo era generar facilidades administrativas y destinar recursos públicos para apoyar la inversión y el establecimiento de negocios privados en la ciudad, bajo el discurso de la competitividad, el beneficio a la comunidad y la generación de empleos (Delgadillo, 2014), permitieron a este eje recuperar su rentabilidad y competir con Santa Fe en el interés del capital inmobiliario.

Estos instrumentos han desencadenado un proceso sin precedente de inversión del capital inmobiliario-financiero nacional y trasnacional como uno de los principales ámbitos territoriales de reinserción de terrenos a la actividad constructora, de recuperación e incremento de rentas del suelo monopólicas y de localización, de procesos de acumulación ampliada del capital inmobiliario-financiero, como soporte material de actividades terciarias y de gestión del gran capital y lugar de residencia temporal o permanente de la elite de sus operadores (Parnreiter, 2011), procesos de integración económica, mundialización y modernización que se desarrollan a nivel global y generan una refuncionalización del espacio, básicamente controlados por estrategias empresariales y sesgos tendencialmente privatizadores (Ciccolella, 2011). 
Cuatro aspectos importantes a señalar en el esquema inmobiliario aplicado: a) La introducción de la innovación del edificio mixto de vivienda de lujo, comercio, oficinas y hotelería, en diversas combinaciones, la cual impulsa, no rompe, el carácter terciario dominante del corredor; $b$ ) la utilización intensiva del terreno mediante la construcción en altura, que permite mantener la rentabilidad a pesar del alto costo del suelo; c) cada gran proyecto anunciado y, sobre todo, realizado eleva las rentas del suelo y el valor de los terrenos existentes, mejora la imagen y la rentabilidad general del corredor, justificando nuevos proyectos en un efecto de cascada; $\mathrm{y} d$ ) los muy elevados costos del metro cuadrado de construcción resultante, por lo general en dólares, llevan a la especialización del corredor en vivienda para los sectores de altos ingresos, oficinas para grandes empresas trasnacionales, hoteles de gran turismo, comercios para este tipo de usuarios, etcétera.

Reforma es hoy la vitrina de la gran arquitectura y los arquitectos empresarios más cotizados en el mercado profesional nacional y, también, extranjeros (figura 1, cuadro 1 y 2). Sin embargo, como señala Harvey (2012) para diversas ciudades actuales, el acelerado crecimiento del capital inmobiliario-financiero nacional y trasnacional ha provocado una especulación financiera desmedida y se ha convertido en una auténtica orgia de destrucción creativa, en particular el desbordamiento delirante de la urbanización capitalista.

\subsection{Reforma y la reestructuración urbana}

Cuando a finales de la década de los setenta, y sobre todo a partir del ajuste neoliberal, se hizo evidente la tendencia a la formación de corredores urbanos terciarios que reestructuraban la centralidad ampliada y tomaban el lugar de las subcentralidades, modificando la lógica de estructuración urbana, Reforma apareció naturalmente como uno de ellos, de importancia metropolitana y alta densidad (Pradilla-Cobos y Pino-Hidalgo, 2004; Márquez-López, 2012), ubicado estratégicamente como eje de relación y movilidad entre el Centro Histórico patrimonial, administrativo y turístico, la centralidad ampliada en disolución, la zona cultural y recreativa del Bosque de Chapultepec, áreas residenciales de sectores de altos ingresos como Polanco y Lomas de Chapultepec, y el Desarrollo Santa $\mathrm{Fe}$-corporativo y residencial de lujo-impulsado entonces por el gobierno Salinas-Camacho, dotado además de un notorio simbolismo urbano heredado de su historia y su apropiación clasista.

Luego de varias décadas de consolidación y densificación, Paseo de la Reforma está entrelazado y fuertemente relacionado en la trama de corredores terciarios metropolitanos, al articularse directamente con otros 


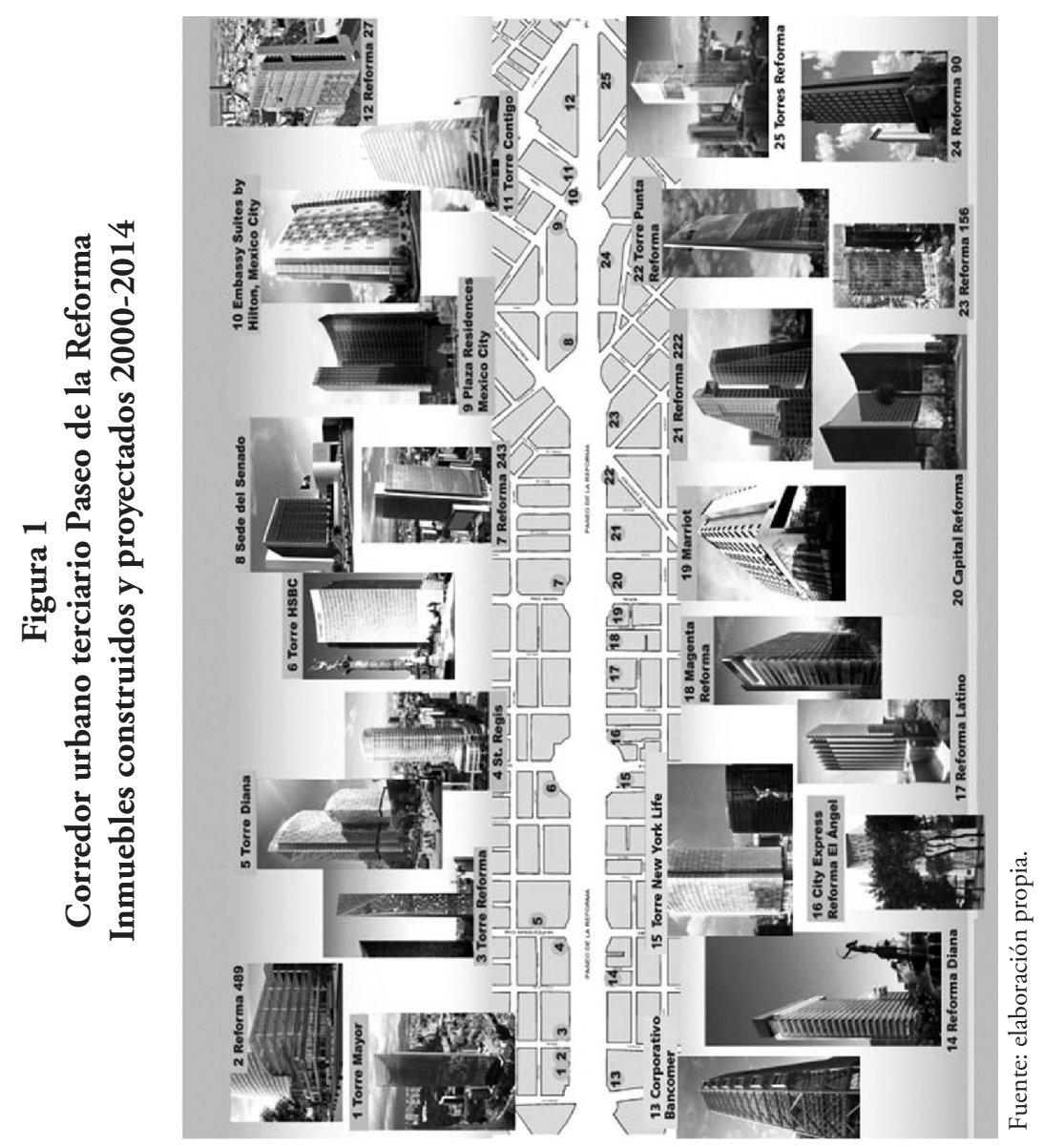




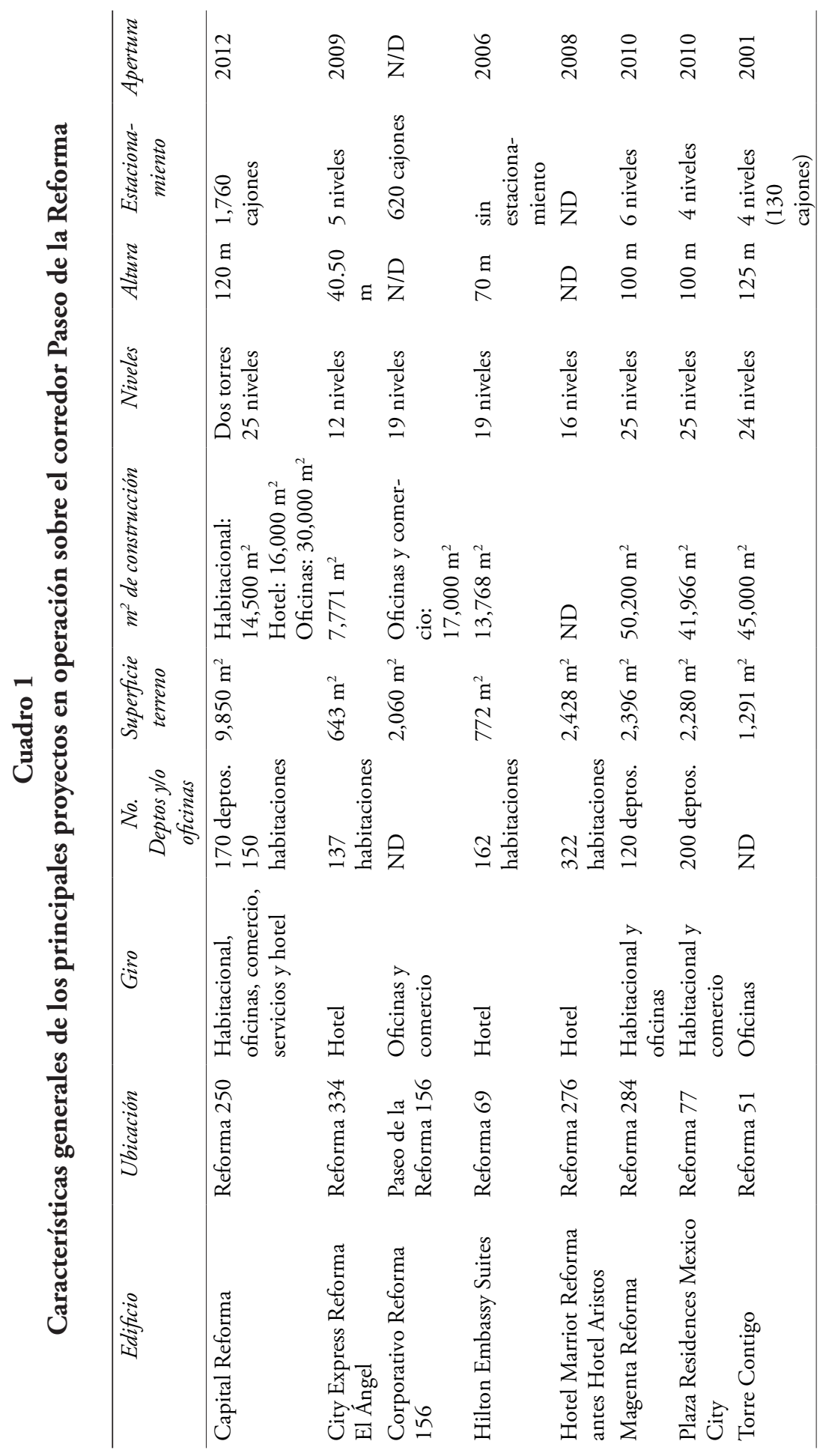




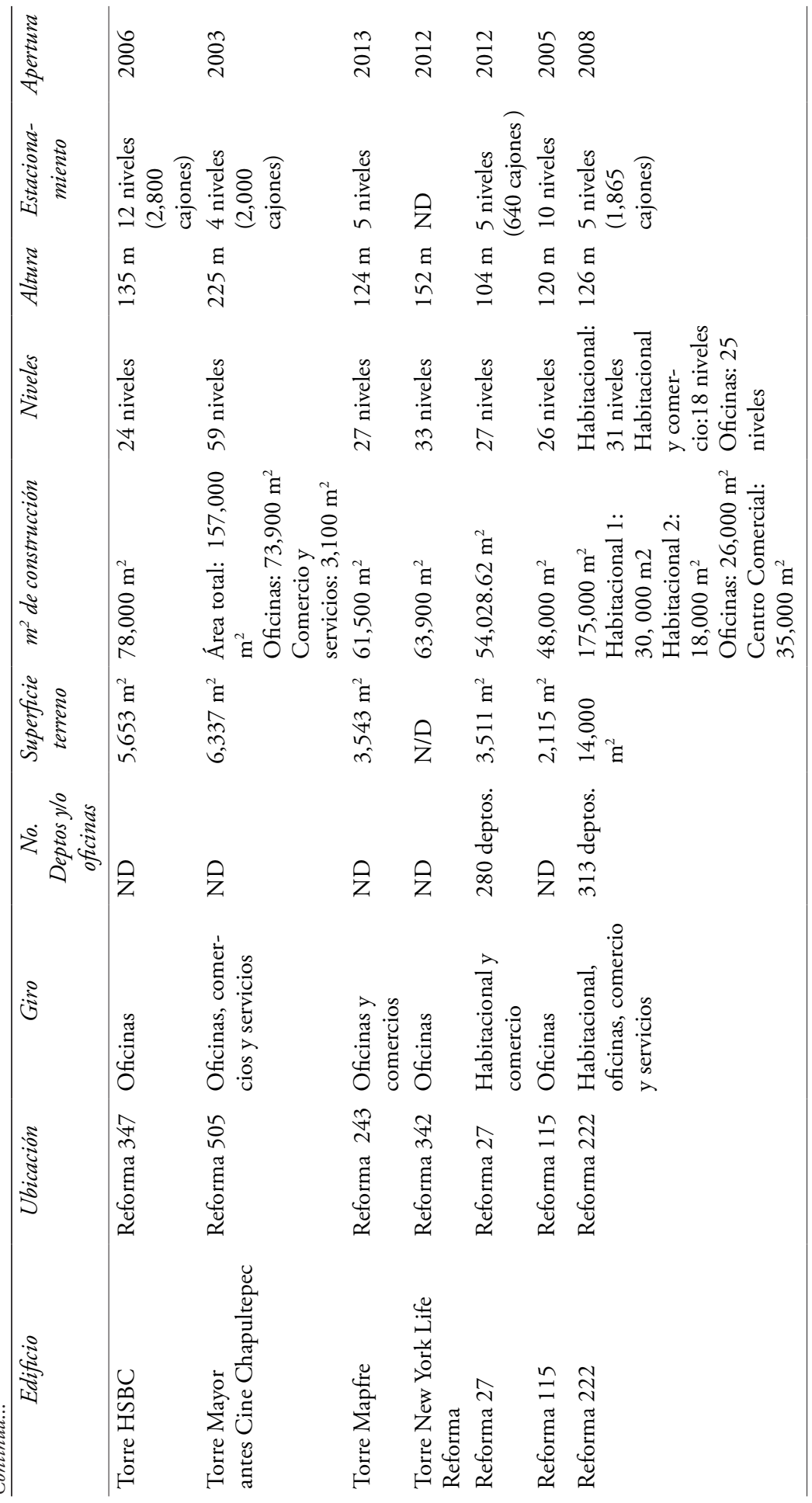




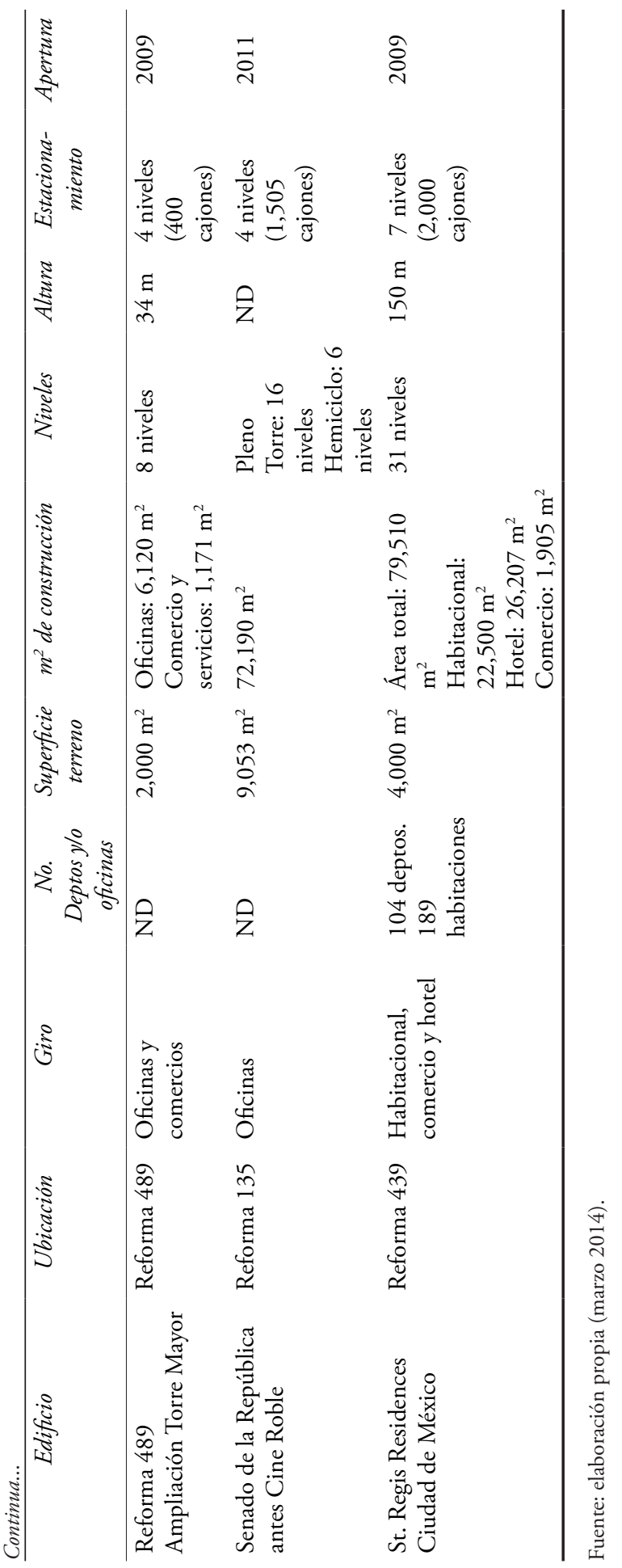




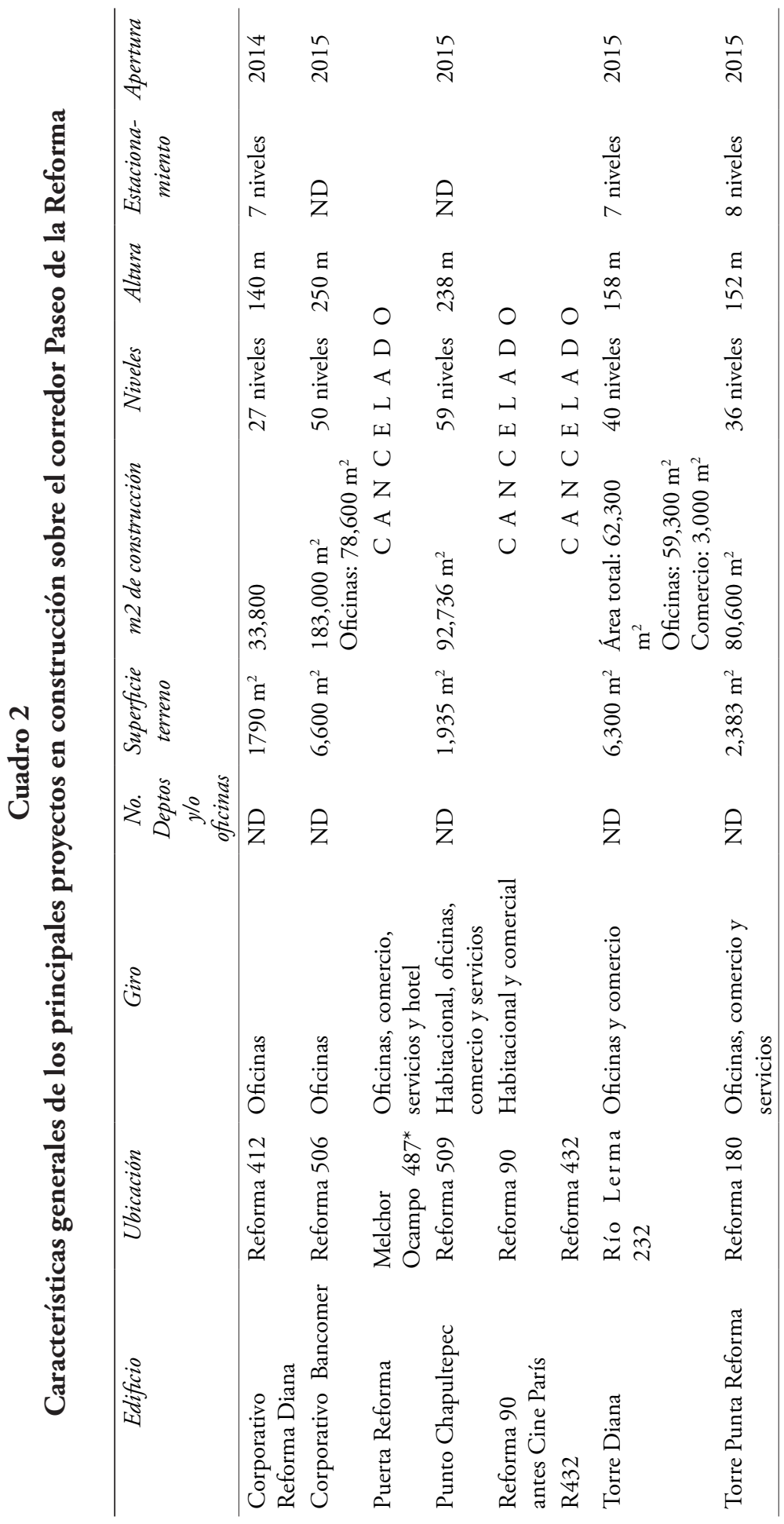




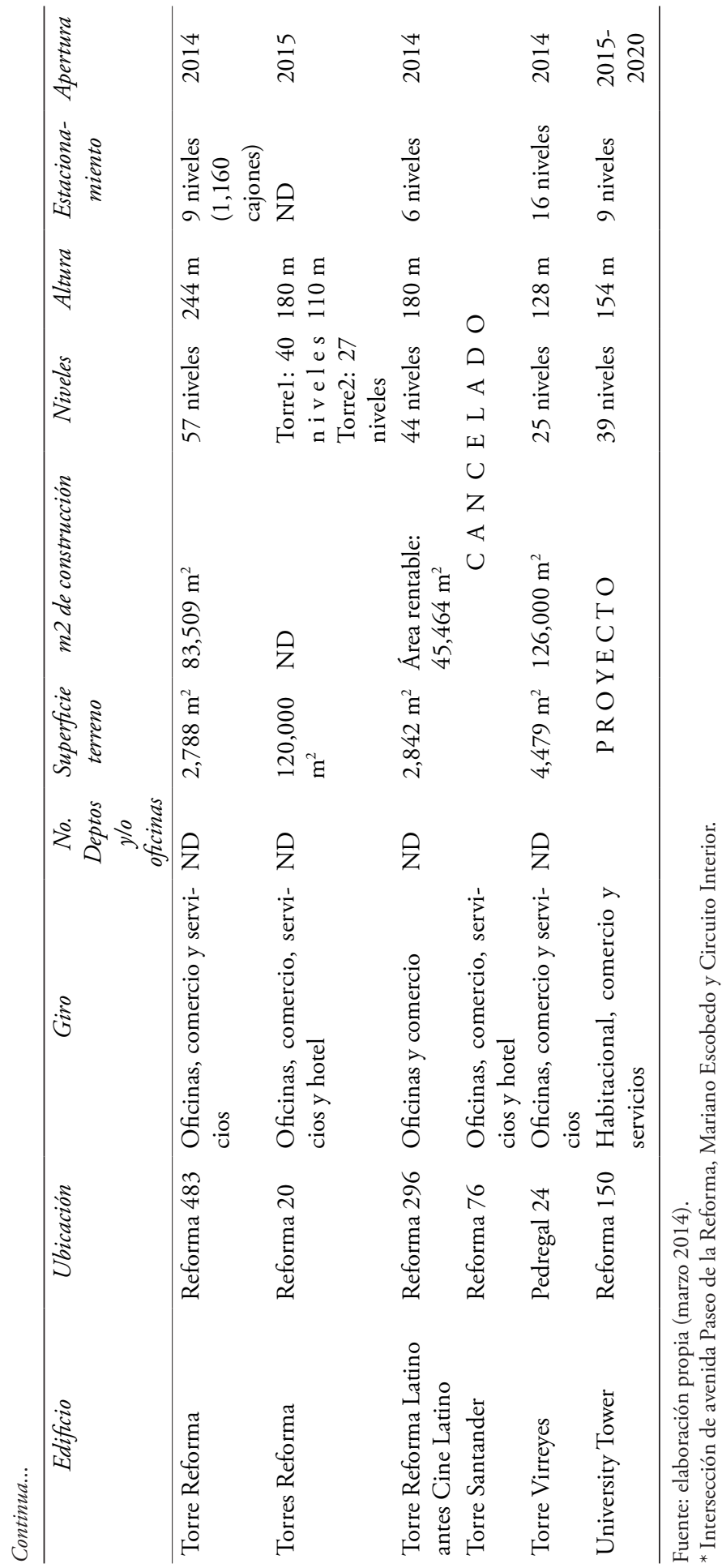


corredores terciarios de menor y desigual desarrollo y densificación como Avenida Juárez, Balderas, Insurgentes, Chapultepec, Circuito Interior y Periférico Centro-Norte, siendo el dominante entre ellos; indirectamente, a través de Mariano Escobedo, se articula con Ejército Nacional y Avenida Palmas, convertidos también en ejes de zonas donde se desarrollan intensas actividades inmobiliarias de construcción de centros comerciales, edificios corporativos y mixtos de oficinas y de vivienda para sectores de altos ingresos (figura 2). Las características específicas de los procesos de reconstrucción actuales y su papel histórico han convertido a Reforma en el corredor terciario más importante y emblemático entre los 108 que actualmente estructuran la ZMVM. ${ }^{1}$

La articulación entre Reforma, Palmas, Constituyentes y Santa Fe, sus procesos de modernización mediante proyectos inmobiliarios y las acciones para mejorar la conectividad entre ellos, emprendidas por los tres últimos gobiernos de la Ciudad de México, hacen que Reforma compita ventajosamente contra el papel de la antigua centralidad histórica, tomando más difícil su mantenimiento como núcleo de una hipotética centralidad única, urbana y renovada, que estuvo, formalmente al menos, en el discurso del Bando 2 de AMLO.

\subsection{Reforma y la política urbana pragmática}

A partir del 2000 confluyeron sobre Reforma varios procesos económicos, políticos e ideológicos que llevaron a una intensa y acelerada reconstrucción y densificación inmobiliaria:

a) La reducción del dinamismo económico y la desindustrialización, entendida como pérdida absoluta de la base productiva ocurrida en la zMVM desde 1982, con un impacto negativo sobre la generación de empleos (Márquez-López y Pradilla-Cobos, 2008), han llevado a la emergencia del sector inmobiliario como el sustituto para la generación de valor y de empleo en el imaginario de los gobernantes capitalinos, sobre todo en los periodos de gobierno local de Marcelo Ebrard (2006-2012) y lo transcurrido del de Miguel Ángel Mancera (2012-2018), sin tener en cuenta el carácter abiertamente cíclico, temporal y de generación de trabajo precario y mal remunerado que tiene el sector.

${ }^{1}$ Pradilla y Pino plantean la constitución de una nueva forma de estructuración de la ciudad, independiente de la dominación de la antigua centralidad, y en particular de su centro histórico paulatinamente marginalizado: la metrópoli se estructura como una gran red de corredores urbanos terciarios con una escala de influencia metropolitana, urbana o barrial local, con diferentes grados de consolidación y saturación, donde la densidad de la actividad terciaria y la intensidad de los flujos humanos y materiales varía; en muchos casos, los corredores son discontinuos, debido a elementos urbanos muy importantes como Ciudad Universitaria, o a zonas habitacionales aún no transformadas (Pradilla-Cobos y Pino-Hidalgo, 2004). 


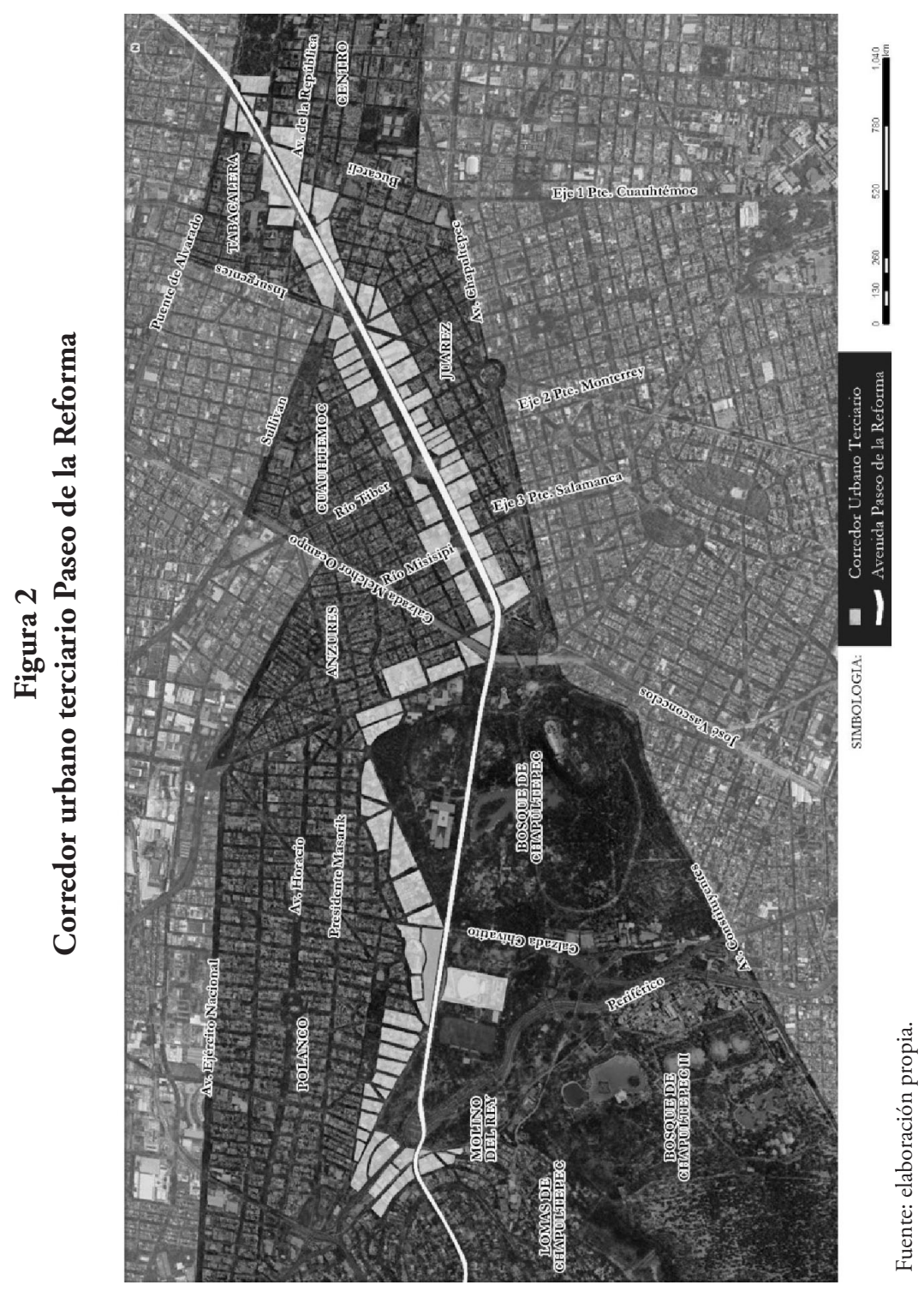


b) A partir del 2000, el Gobierno del Distrito Federal (GDF) tomó la opción del apoyo explícito y abierto a la reconstrucción del corredor urbano Paseo de la Reforma, mediante incentivos y desgravaciones tributarias, facilidades administrativas y programas de inversiones directas para la modernización de la infraestructura y el embellecimiento, en el marco del Bando 2, política urbana vigente entre 2000 y 2007, encaminada a la redensificación y revitalización de la "centralidad".

c) Esta opción fue reafirmada a partir de 2006, pues los dos sucesivos jefes de GDF consideraron al capital inmobiliario y al sector terciario como opciones "de desarrollo y creación de empleo para la ciudad", a los megaedificios como "elementos icónicos de competitividad global" (la Torre Mayor, la de BBVA Bancomer o la frustrada Torre Bicentenario, entre otros), y al mega-túnel Santa Fe-Reforma, como parte de su proyecto prioritario de conectividad y movilidad automotriz, que no se realizó debido a la crisis económica que estalló en 2009, meses después de su anuncio.

d) En el marco de la "libre circulación mundial de capitales" introducida por el patrón neoliberal de acumulación, han arribado a la ciudad capitales financieros especulativos trasnacionales para la inversión en el sector inmobiliario, que operan independientemente o asociados con el capital nacional, y en particular a sus espacios privilegiados: el Desarrollo Santa Fe, las barrancas de Cuajimalpa y Álvaro Obregón, Polanco y el eje Reforma.

e) Los instrumentos legales como la fusión de terrenos, la creación de polígonos de actuación, la transferencia de potencialidades, la sustitución de las licencias previas de construcción y de formación de polígonos de actuación por las "manifestaciones de obras", la reciente simplificación y centralización de los cambios de usos del suelo en el ejecutivo central del DF -modificación de la Ley de Desarrollo Urbano del Distrito Federal en el 2010- (ALDF, 2010), permiten adecuar la débil planeación urbana existente a los intereses del capital inmobiliario orientado a recuperar las rentas monopólicas y de localización del suelo generadas en Reforma y otras áreas por el crecimiento urbano metropolitano y las mismas inversiones inmobiliarias, y a reproducir su capital en los ciclos de construcción de inmuebles en altura.

f) La paulatina conclusión del ciclo de recuperación del capital invertido en los viejos inmuebles construidos en Reforma a mediados del siglo $\mathrm{xx}$, abrió la posibilidad de realizar nuevos procesos de valorización mediante nuevas inversiones inmobiliarias.

g) El protagonismo obtenido en la escena urbana mundial por los nuevos artefactos arquitectónicos (inmuebles plurifuncionales, edificios cerrados e "inteligentes", centros comerciales, etc.), penetró ampliamente 
en el imaginario de los gobernantes de todos los signos políticos, incluidos los "de izquierda", y en el de la sociedad en su conjunto, como símbolos de "desarrollo y modernidad" (Pradilla-Cobos, 2010).

h) Se ha generalizado el patrón de incremento de altura de las torres, como instrumento para el uso intensivo del suelo con el fin de reducir el impacto de sus muy elevados precios en el mercado sobre el precio de producción por unidad de superficie construida, como forma de competencia entre firmas y capitales, y como elemento icónico-simbólico.

I) Se reproduce la ideología neoliberal del valor de la iconografía inmobiliaria en la competitividad global de las ciudades, que ha capturado también a los gobernantes "de izquierda" de la ciudad.

En síntesis, objetivamente, la acción gubernamental en lo normativo y regulatorio, la simplificación administrativa, los estímulos y exenciones fiscales, la inversión directa y la difusión ideológica y publicitaria han sido sustantivos en la reconstrucción de Reforma.

La política gubernamental de apoyo a la modernización y densificación de Reforma ha entrado en contradicción con la de fortalecimiento y revitalización de la centralidad, reduciendo al Centro Histórico al papel de ámbito secundario, subordinado, especializado mediante su "revalorización" o "puesta en valor", en el patrimonio histórico, la cultura, el turismo, en la parte conocida como "corredor financiero", y en el comercio popular en las áreas no rentables para el capital.

El "desarrollo moderno" de Santa Fe, Polanco y Reforma ha hecho parte, implícita pero objetivamente, del proyecto de ciudad de los tres últimos gobernantes del Distrito Federal, pero no aparece explícitamente en el único Programa de Desarrollo Urbano del Distrito Federal aprobado en el periodo (GDF, 2003) ni se ha sometido a consulta pública, aunque se incluye abierta o veladamente en el discurso de los gobernantes; y su promoción e impulso se ha llevado a cabo mediante acciones pragmáticas. La reconstrucción en curso del Paseo de la Reforma expresa la naturaleza subordinada de las políticas urbanas de los gobiernos federal y del Distrito Federal a los intereses y proyectos del conjunto del capital, en particular el inmobiliario-financiero nacional y trasnacional, independientemente del lugar opuesto que afirman ocupar en la geometría político-ideológica nacional.

El estado y el sistema político mexicanos no han dejado de lado ni abandonado el contenido simbólico-político del Paseo de la Reforma. A su reforzamiento se destinaron dos grandes obras: la construcción del Senado de la República en la intersección con la avenida Insurgentes, frente al monumento a Cuauhtémoc; y la Estela de Luz, como monumento conmemorativo del Bicentenario de la Independencia y del Centenario de la Revolución mexicana. Pero ambas, han estado signadas por el largo retraso en su con- 
clusión y los rumores a gritos de corrupción presupuestal, y parecen reflejar la crisis del sistema político mexicano más que su gloria.

Los procesos de modernización sufridos por el Paseo de la Reforma (mediados del siglo xx e inicios del xxi) han dejado como "daño colateral" la casi total destrucción de los inmuebles de fines del siglo XIX e inicios del xx, de arquitectura art déco, nacionalista, ecléctica o aún moderna que lo caracterizaron, poco protegidos por la legislación y la acción urbano-arquitectónica pública, que junto con el proceso similar acaecido en la colonia Roma, han dejado a la ciudad sin muestras integradas y significativas de ese patrimonio cultural decimonónico y de los inicios del siglo XX.

\subsection{La apropiación social y política del paseo y sus contradicciones}

El Paseo de la Reforma integra ahora, fundamentalmente, usos del suelo terciarios, soportes materiales de la actividad bancaria y financiera, de la gestión empresarial, los servicios especializados para la economía, la hotelería y servicios conexos, la gastronomía, la recreación y centros comerciales de amplio espectro. La construcción de vivienda nueva también se ha hecho presente a lo largo del corredor, estas nuevas edificaciones destacan por integrar departamentos de lujo, de una, dos y tres recamaras, con una superficie de construcción desde los 55 hasta los $250 \mathrm{~m}^{2}$, dotados con servicios al interior del inmueble: alberca, gimnasio, spa, áreas verdes, juegos infantiles, salones de fiesta, centro de negocios, centros comerciales y estacionamientos, características que sumadas a las ventajas de localización y el prestigio de la zona, llevan a que el precio promedio del metro cuadrado de los departamentos a la venta sea de 45 mil 500 pesos.

La presencia mayoritaria del capital financiero-inmobiliario de origen trasnacional, así como de empresas trasnacionales en los giros bancariofinancieros, hoteleros, de servicios, etc. (Parnreiter, 2011), dan al Paseo de la Reforma, en lo que se refiere al uso privado de los inmuebles, un carácter de corredor trasnacional, cosmopolita, dirigido a los sectores de altos ingresos y excluyente de otros sectores sociales que actúan en él como trabajadores asalariados, usuarios ocasionales o simples transeúntes.

La naturaleza estructural y funcional de estos artefactos urbano-arquitectónicos de elite, de fría arquitectura posmoderna, multifuncionales, integrados internamente pero desintegrados de su entorno, hechos para el acceso por automóvil, de ingreso restringido, cerrados hacia el exterior, vigilados por policías privadas y sistemas electrónicos, no añaden vida al entorno urbano. Han expulsado del entorno a los sectores de menores ingresos que aún residían allí, dando lugar a un cambio sustantivo de sector social residente y usuario; y al mismo tiempo han generado un 
repliegue hacia los espacios privados y han contribuido al debilitamiento de lo público como espacio de comunicación entre miembros diferentes de la sociedad (Ramírez-Kuri, 2014).

Lo que evidentemente no ha formado parte de las preocupaciones de los inversionistas modernizadores es la satisfacción de las necesidades básicas de alimentación y otros consumos de los sectores de trabajadores de bajos ingresos que laboran en los complejos inmobiliarios, los cuales no pueden resolver en los comercios de lujo y que deben atender en pequeños comercios en las áreas traseras del corredor, mucho menos valorizadas, o en el comercio informal en la vía pública, perseguido por los agentes gubernamentales en el corredor para "no dañar la imagen urbana", pero que se refugia en las calles de atrás del corredor.

Como contratendencia al carácter elitista y desalojo de residentes y usuarios populares, y porque el imaginario colectivo reconoce al corredor como escenario de la modernidad o de la tradición, socialmente muy visible, el Paseo de la Reforma, como espacio público, es utilizado para eventos publicitarios mercantiles del capital, o por los gobiernos federal y del Distrito Federal, como ámbito de festividades recreativas masivas de todo tipo, o escenario popular de fines de semana bicicleteros familiares.

Los sindicatos, las organizaciones sociales y los partidos políticos usan el paseo, y en especial el Monumento al Ángel de la Independencia por su significación y simbolismo, para realizar mítines políticos, electorales o manifestaciones de protesta callejera transitoria o de larga duración; aún AMLO, que impulsó el desarrollo del paseo cuando fue Jefe de Gobierno, lo mantuvo ocupado e inhabilitado por más de un mes durante su protesta por el supuesto "fraude electoral" en las elecciones presidenciales del 2006. Desde 1986, el ángel también ha sido utilizado como espacio de expresión popular al realizar celebraciones con connotaciones apolíticas, en el nombre de la patria, como el festejo de los triunfos o clasificaciones de la selección mexicana de futbol en las copas del mundo.

Estos usos del paseo, únicas actividades que expresarían una apropiación colectiva, pero marginal, del corredor por la ciudadanía, se contraponen, pues el uso público afecta la libre circulación automovilística de los usuarios privados de los inmuebles, y en su vertiente políticosocial les crea un fantasma de inseguridad. Ambos modos de uso público anaden al carácter dominante eminentemente mercantil que ha adquirido el corredor, pinceladas populares, democráticas, culturales, políticas, que le dan, en momentos particulares, un toque de apropiación colectiva, ciudadana, de vida comunitaria. 


\subsection{Un cambio dominado por la rentabilidad inmobiliaria y el prestigio político}

El paseo, desde su trazo inicial por el emperador Maxilmiliano o su consolidación como paseo y eje principal de una zona residencial durante el gobierno dictatorial de Porfirio Díaz, hasta su auge actual como corredor terciario urbano, ha sido un ámbito residencial aristocrático u operativo y de gestión del capital industrial, comercial, financiero, hotelero, de servicios y otros sectores, un objeto de la acumulación del capital inmobiliario y financiero, un icono ideológico del poder económico de los sectores de altos ingresos y del poder político de la burocracia, y un territorio privilegiado de la política y la acción urbana estatal.

Actualmente, el paseo aparece, junto con Santa Fe, Polanco, Insurgentes Sur y los macro desarrollos inmobiliarios de micro viviendas "de interés social" en los municipios conurbados (Duhau, 2008; PradillaCobos, 2010), como uno de los ámbitos más significativos de la reproducción urbana de la ZMVM en la mundialización neoliberal, ${ }^{2}$ tanto por la combinación de capitales inmobiliarios y financieros nacionales y extranjeros que los producen y gestionan, como por el uso por el gran capital trasnacional y sus agentes de los inmuebles producidos (Parnreiter, 2011), como por la polarización social extrema que exhiben sobre el territorio metropolitano.

El corredor Reforma es el escenario de una gran operación de regeneración de rentas del suelo, en particular absolutas, de monopolio y de localización, mediante la utilización de terrenos ociosos o la destrucción de inmuebles obsoletos ya amortizados -en las condiciones actuales- y la inversión de capital privado en la construcción de nuevas obras arquitectónicas con mayor intensidad de construcción, o de recursos públicos en infraestructura y servicios. El Paseo de la Reforma es, al mismo tiempo, el ámbito de una gigantesca inversión de capital inmobiliario, alimentada por el capital financiero, ambos de origen mixto nacional y trasnacional, materializada en inmuebles con alta intensidad constructiva y modalidades de usos mixtos facilitados por la legislación y la gestión pública mediante mecanismos legales como la fusión de predios, los polígonos de actuación y la transferencia de potencialidades.

\footnotetext{
${ }^{2}$ En ese sentido, desempeña un papel similar al del eje de Puerto Madero en Buenos Aires, el corredor de La Costanera en Santiago de Chile, Puerto Maravilla en Río de Janeiro, la Avenida Balboa en Panamá, entre otros ejemplos de desarrollos inmobiliarios globales en América Latina, que constituyen actualmente áreas privilegiadas de inversión del capital inmobiliario financiero en esas ciudades. Para un mejor desarrollo ver: Pradilla-Cobos, 2010.
} 
Desde el punto de vista de la acumulación de capital, en el boom inmobiliario en Reforma se funden dialécticamente ${ }^{3}$ las rentas del suelo, la ganancia en la producción de los inmuebles, los intereses del crédito bancario, la ganancia comercial en la venta o renta de los inmuebles y las ganancias de otros sectores como los servicios especializados de diseño, contaduría, etcétera.

\section{Conclusiones}

Desde su origen, el Paseo de la Reforma fue resultado del interés y de las acciones del poder político y uno de los ejes de aglomeración del poder económico, primero de sus residencias y lugares de entretenimiento y luego de lugares comerciales, de servicio y gestión. Desde entonces y hasta la fecha, el Paseo ha conservado su simbolismo como eje del poder, y en él se siguen depositando, como desde sus inicios, una serie de intereses económicos y políticos que han incentivado la inversión de capitales inmobiliarios y financieros nacionales y extranjeros.

Actualmente, la gran magnitud de capital inmobiliario-financiero invertido en el paseo, hace posible la construcción de nuevas obras arquitectónicas con mayor intensidad de construcción, monumentalidad, presencia de prestigiadas cadenas multinacionales de hotelería y servicios; elementos que, según el discurso gubernamental, en el pasado y actualmente sirven para mostrar a la Ciudad de México como una ciudad moderna, competitiva y exclusiva, a la altura de las grandes ciudades desarrolladas.

El proyecto de recuperación de Reforma, además de aprovechar las ventajas de localización y aglomeración existentes en la zona y de transformar la fisonomía del corredor, ha generado procesos contradictorios: mayor penetración comercial y de servicios y nueva actividad económica, mayor densidad de población residente, trabajadora o usuaria, incremento de la población flotante, aumento en el número de desplazamientos, uso indiscriminado del automóvil, generación de tráfico y disminución de movilidad, etcétera.

Aunque entre los desarrollos inmobiliarios construidos exista un gran número de edificios denominados "sustentables" que ahorren agua, energía, etc., éstos necesariamente generan una mayor demanda de infraestructura de transporte y estacionamiento, servicios de energía eléctrica, agua potable, drenaje y recolección de desechos y mayor contaminación

\footnotetext{
${ }^{3}$ La magnitud elevada de las rentas y precios del suelo determina la construcción en altura con elevada intensidad de construcción orientada a sectores empresariales o de altos ingresos; la magnitud de la inversión inmobiliaria y la naturaleza de los usuarios eleva nuevamente las rentas y precios del suelo que inciden en la orientación de los inmuebles hacia compradores y usuarios de elite.
} 
ambiental, por el incremento de la población residente, trabajadora y usuaria de la zona, lo cual pone en duda su sustentabilidad ambiental y sostenibilidad económica en términos colectivos. Al mismo tiempo, la densificación de Reforma acentúa los déficits de infraestructuras (vialidad) y servicios (agua potable, drenaje, energía) en otros ámbitos de la ciudad que la inversión focalizada no resuelve ni son tenidos en cuenta en los estudios de impacto urbano y ambiental presentados por los megaproyectos de Reforma.

A pesar de estas contradicciones, el Paseo de la Reforma sigue y, probablemente, seguirá siendo durante al menos una década el lugar indicado para desarrollar grandes proyectos urbano-arquitectónicos, porque para el capital inmobiliario nacional y trasnacional representa un área de alta rentabilidad económica; y porque para el GDF aparece como una zona icónica del "avance económico y tecnológico" de la capital y de su anhelada ubicación como "ciudad de clase mundial". Luego, concluido el proceso intenso de modernización actual, vendrá un periodo de agotamiento de los terrenos y desaceleración de la inversión y muy posiblemente Reforma será sustituido por otra zona u otro corredor terciario como ámbito privilegiado de inversión de capital inmobiliario y de la ideología recurrente de la modernización urbana.

Para concluir, habrá que señalar dos paradojas mayores del proceso de reactivación-transformación del Paseo de la Reforma, promovido por los tres gobiernos sucesivos del PRD desde 2000: los inmuebles construidos o proyectados en la zona en el periodo están destinados a actividades empresariales o a vivienda permanente o transitoria (hoteles) para sectores de muy altos ingresos, es decir, que se trata de un ambiente excluyente de los sectores populares; y el proyecto ha buscado explícitamente convertir al paseo en un área destinada a la acumulación del gran capital inmobiliario-financiero nacional y trasnacional; es decir, adecuar al paseo a las exigencias reales, imaginarias o deseadas de la globalización del capital.

La contradicción central del proyecto de Paseo de la Reforma, íntimamente ligada al de adecuación de la infraestructura vial a la movilidad en automóvil individual, ambos realizados por el capital privado trasnacionalizado, radica en que este proyecto de modernización capitalista neoliberal de la ciudad está siendo llevado a cabo por gobiernos que se proclaman de izquierda.

\section{Fuentes consultadas}

Alfaro, Francisco Haroldo y Alejandro Ochoa (1997), Espacios distantes... aún vivos. Las salas cinematográficas de la Ciudad de México, Universidad Autónoma Metropolitana unidad Xochimilco, México. 
Arciniega-Ávila, Hugo (1994), "El xIx otro siglo de utopías”, en Gladis Sirvent-Gutiérrez y Francisco Haroldo Alfaro, Colonia Tabacalera: varias lecturas sobre patrimonio, Universidad Autónoma Metropolitana unidad Xochimilco, México, pp. 39-74.

ALDF (Asamblea Legislativa del Distrito Federal) (2010), Ley de Desarrollo Urbano del Distrito Federal, Gobierno del Distrito Federal, México.

Ciccolella, Pablo (2011), Metrópolis latinoamericanas: más allá de la globalización, Organización Latinoamericana y del Caribe de Centros Históricos, Quito.

Delgadillo, Víctor (2014), "Ciudad de México: megaproyectos urbanos, negocios privados y resistencia social", en Rodrigo Hidalgo y Michael Janoschka, La ciudad neoliberal. Gentrificación y exclusión en Santiago de Chile, Buenos Aires, Ciudad de México y Madrid, Pontificia Universidad Católica de Chile, Santiago, pp. 199-215.

Duhau, Emilio (2008), "Los nuevos productores del espacio habitable", Ciudades, núm. 79, Red Nacional de Investigación Urbana, Puebla, pp. 21-27.

Gayón-Córdova, María (1987), "Los servicios públicos en la ciudad de México en el siglo XIx", en Gustavo Garza (comp.), Atlas de la ciudad de México, Departamento del Distrito Federal y El Colegio de México, México, pp. 71-74.

Gilly, Adolfo (2007), La revolución interrumpida, Ediciones Era, México.

GDF (Gobierno del Distrito Federal) (2003), Programa General de Desarrollo Urbano del Distrito Federal, Gaceta Oficial del Distrito Federal, México.

Gómez, Amparo (1994), “El Paseo de la Reforma 1864-1910”, en Wendy Coss y León (ed.), Historia del Paseo de la Reforma, Instituto Nacional de Bellas Artes y Democracia Editores, México, pp. 27-53.

Harvey, David (2013), Ciudades rebeldes. Del derecho de la ciudad a la revolución urbana, Ediciones Akal, España. 
Jiménez-Muñoz, Jorge (1993), La traza del poder: historia de la política y los negocios urbanos en el Distrito federal. De sus origenes a la desaparición del ayuntamiento, 1824-1928, Dédalo, México.

Jiménez-Muñoz, Jorge (1994), "El Paseo, del Imperio a la Reforma”, en Wendy Coss y León (ed.), Historia del Paseo de la Reforma, Instituto Nacional del Bellas Artes y Democracia Editores, México, pp. 55-63.

Márquez-López, Lisett (2012), "Cambios en la estructura urbana y formación de un corredor urbano terciario. Paseo de la Reforma 19702007", tesis de doctorado, Universidad Nacional Autónoma de México, México.

Márquez-López, Lisett y Emilio Pradilla-Cobos (2008), “Desindustrialización, terciarización y estructura metropolitana: un debate conceptual necesario", Cuadernos del CENDES, núm. 69, Universidad Central de Venezuela, Venezuela, pp. 21-45.

Martínez-Assad, Carlos (2005), La patria en el Paseo de la Reforma, Fondo de Cultura Económica, México.

Martínez de la Macorra, Cecilia y Luis Gabriel Juárez (1994), La Lotería Nacional y su ámbito urbano. La puerta al México moderno, Universidad Nacional Autónoma de México, México.

Parnreiter, Christof (2011), "Formación de la ciudad global, economía inmobiliaria y trasnacionalización de espacios urbanos. El caso de Ciudad de México", Eure, 37 (111), Pontificia Universidad Católica de Chile, Santiago, pp. 5-24.

Pradilla-Cobos, Emilio y Ricardo Pino-Hidalgo (2004), "Ciudad de México: de la centralidad a la red de corredores urbanos", Anuario de Espacios urbanos 2004, Universidad Autónoma Metropolitana unidad Azcapotzalco, México, pp. 71-96.

Pradilla-Cobos, Emilio, Lisett Márquez-López, Saúl Carreón-Huitzil y Elías Fonseca (2008), "Centros comerciales, terciarización y privatización de lo público”, Ciudades, núm. 79, Red Nacional de Investigación Urbana, Puebla, pp. 44-53. 
Pradilla-Cobos, Emilio (2009), Los territorios del neoliberalismo en América Latina, Universidad Autónoma Metropolitana unidad Xochimilco y Miguel Ángel Porrúa, México.

Pradilla-Cobos, Emilio (2010), "Mundialización neoliberal, cambios urbanos y políticas estatales en América Latina”, Cadernos Metrópole, 12 (24), Observatorio das Metrópoles, São Paulo, pp. 507-533.

Pradilla-Cobos et al. (2012), "Changements économiques, sociaux et morphologiques dans la Zone Métropolitaine de la Vallée de Mexico 1982-2010", en Luc-Normand Tellier y Carlos Vainer, Métropoles des Amériques en mutation, Presses de l'Université du Québec, Canada, pp. 52-71.

Pradilla-Cobos, Emilio (2013), "La economía y las formas urbanas en América Latina”, en Blanca Ramírez-Velázquez y Emilio PradillaCobos (comps.), Teorías sobre la ciudad en América Latina, Universidad Autónoma Metropolitana unidad Xochimilco, México, pp. 169-232.

Ramírez-Kuri, Patricia (2014), "La reinvención de la ciudadanía desde el espacio público en la ciudad fragmentada”, Interdisciplina, 2 (2), unaM, México, pp. 71-96.

Terrazas-Revilla, Óscar (2005), "Un modelo explicativo”, en Óscar Terrazas-Revilla (coord.), La ciudad de los caminos, Universidad Autónoma Metropolitana unidad Azcapotzalco, México, pp. 17-50.

Recibido: 6 de junio de 2014. Reenviado: 19 de noviembre de 2014. Aceptado: 30 de enero de 2015.

Lisett Márquez López. Mexicana. Doctora en urbanismo por la Universidad Nacional Autónoma de México. Actualmente realiza una estancia posdoctoral en el Programa de Doctorado en Ciencias Sociales, en la División de Ciencias Sociales y Humanidades en la Universidad Autónoma Metropolitana unidad Xochimilco. Su línea de investigación actual es el análisis de las políticas de rescate del espacio público en el área central de la Ciudad de México y los efectos sobre su apropiación social. Entre sus últimas publicaciones en coautoría destacan: "Changements économiques, sociaux et morfhologiques dans la zone mètropolitaine de 
la valée de Mexico, 1980-2010", en Luc-Nornamd Tellier y Carlos Vainer (comps.), Métropoles des Ameriques en mutation, Presses de l'Université de Québec, pp. 51-70 (2012); "Cambios económicos y morfológicos en la Zona Metropolitana del Valle de México”, en Duhau Emilio, La ciudad de México: La construcción permanente de la Metrópoli, Organización Latinoamericana y del Caribe de Centros Históricos, Quito, pp. 49-91 (2012); "Desindustrialización, terciarización y estructura metropolitana: un debate conceptual necesario", Cuadernos del CENDES, 69, Centro de Estudios de Desarrollo y Universidad Central de Venezuela, Caracas, pp. 21-45 (2008). 